\title{
Girls' leadership and mentoring
}

Karen Austrian

Population Council

Follow this and additional works at: https://knowledgecommons.popcouncil.org/departments_sbsr-pgy

Part of the Family, Life Course, and Society Commons, and the Gender Equity in Education Commons How does access to this work benefit you? Let us know!

\section{Recommended Citation}

Austrian, Karen. 2012. "Girls' leadership and mentoring," GIRLS FIRST! Perspectives on Girl-Centered Programming. New York: Population Council. 
A GIRLS FIRST! PUBLICATION

GIRLS'

LEADERSHIP AND MENTORING

\section{BY KAREN AUSTRIAN}

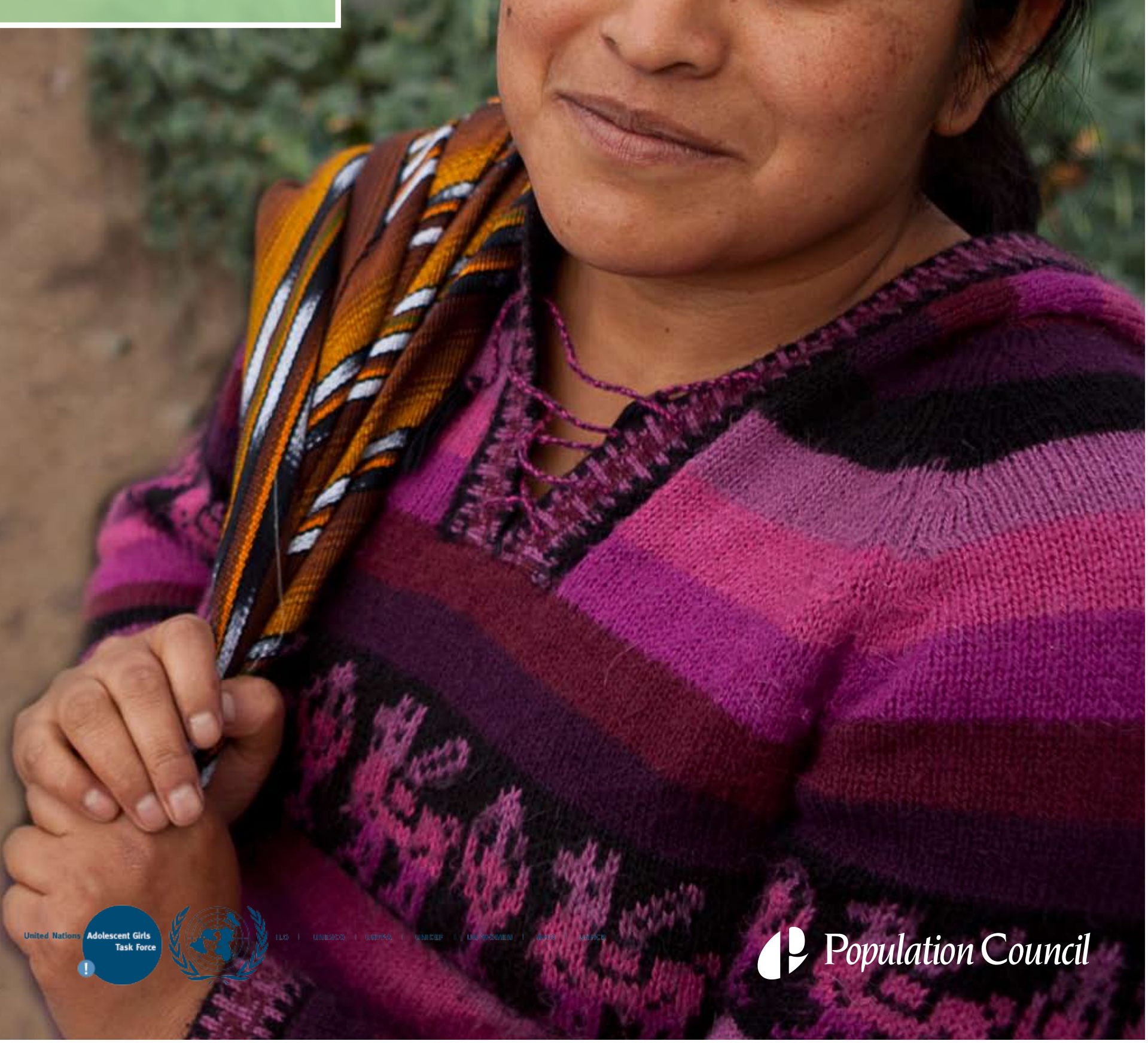




\section{GIRLS FIRST!}

\section{PERSPECTIVES ON GIRL-CENTERED PROGRAMMING}

The field of research and programs for adolescent girls has traditionally focused on sexuality, reproductive health, and behavior, neglecting the broader social and economic issues that underpin adolescent girls' human rights, overall development, health, and well-being. Further, efforts to improve girls' lives often spotlight those who control or influence their lives-parents, in-laws, boys, men, perpetrators-overlooking girls themselves.

GIRLS FIRST! Perspectives on Girl-Centered Programming is a set of five thematic Reviews, written by experts at the Population Council. They are snapshots of the knowledge base at a particular moment in this quickly changing field. They address the five strategic priorities defined in the UN Joint Statement, "Accelerating Efforts to Advance the Rights of Adolescent Girls" (March 2010), which represents the collective commitment of seven UN agencies to support governments and partners in advancing key policies and programs for the hardest-toreach adolescent girls. The Reviews therefore:

1. Explore where to go next with education for girls;

2. Outline innovative approaches to improving girls' health;

3. Reframe the field's approach to violence against girls;

4. Describe the best ways to cultivate girl leaders; and

5. Explain novel ways to collect and use data on adolescent girls.

The Reviews put forward innovative arguments for investing in girls and highlight promising practices. They express a forward-looking and evidence-based point of view on where the field must allocate resources in order to most quickly and effectively improve girls' lives.

These Reviews-while written by experts at the Population Council, an organization that has pioneered cutting-edge research and programming for vulnerable and marginalized adolescent girls-were catalyzed with leadership support from the UN Adolescent Girls Task Force. Additional moral and material support was provided by the Nike Foundation, the United Nations Foundation, and the David and Lucile Packard Foundation. These Reviews add to other programmatic guidance and toolkits now available and serve as an essential reference for anyone seeking to develop successful and sustainable policies and programs for girls. We hope that they will inspire innovative approaches in efforts that realize the rights of marginalized adolescent girls worldwide.

August 2012

Population Council and UN Adolescent Girls Task Force

Disclaimer

The Reviews on programming for adolescent girls in the areas of Education, Health, Reduction of Violence, Girls' Leadership, and Data have been prepared by the Population Council for the UN Adolescent Girls Task Force (UN AGTF), with support from the Nike Foundation, the United Nations Foundation, the David and Lucile Packard Foundation.

The views expressed in these Reviews are solely those of the authors and do not necessarily reflect the views of their donor partners.

(C) 2012 The Population Council, Inc. $\quad$ www.popcouncil.org 


\title{
GIRLS' LEADERSHIP AND MENTORING
}

\author{
BY KAREN AUSTRIAN
}

\section{BASIC KNOWLEDGE AND PREMISES}

Girls have fewer opportunities, compared with boys, to meet same-sex friends, make new friends, and interact with mentors

There are girls with leadership potential in every community in the world

Young girls need local leaders to look up to and emulate

The opportunity to be seen as a leader and mentor in a community

changes a girl's view of herself

The presence of a network of young female leaders (and a safe space that they regularly occupy) implicitly and explicitly challenges the power structure within a community and lends a

strong female voice to decision-making structures in the community

PROMOTED POLICIES AND PRACTICES

Cascading Leadership: Begin with the girls' leadership that exists where you are;

build program models from there

Train older adolescent girls or young women to be leaders within their own communities

and run programs for younger adolescent girls

Support mentors with appropriate compensation

Provide mentors with ongoing supervision and support

Involve girls in identifying the most appropriate content and delivery methods for their program

Employ leaders and mentors who are themselves girls; they are often the most effective and sustainable in the long term in delivering content to other girls in their community

Recognize that mentors and peer educators are two different models that serve different purposes

Experiment with content once a structure is in place

\section{RESOURCES: LEARNING LAB PROGRAMS}

The Binti Pamoja (Daughters United) Center Safe Spaces Program: An asset-building program

for adolescent girls aged 10-19, Kibera, Kenya

Safe and Smart Savings Products for Vulnerable Adolescent Girls in Kenya and Uganda:

Building girls' leadership and access to financial products

Abriendo Oportunidades (Opening Opportunities): Program for rural, indigenous girls ages 8-18

from Guatemala's poorest communities

Biruh Tesfa (Bright Future): Program for domestic workers and rural-urban migrants

in Ethiopia's slum areas

\section{RESOURCES: PUBLICATIONS AND TOOLS}

Girl-Centered Program Design: A Toolkit to Develop, Strengthen \& Expand Programs for Adolescent Girls 


\section{BASIC KNOWLEDGE AND PREMIISES}

Girls have fewer opportunities, compared with boys, to meet same-sex friends, make new friends, and interact with mentors ${ }^{1}$

Several surveys assessing girls' social networks have indicated that girls do not have the same social opportunities as boys do. For example, in the Kibera slum of Nairobi, Kenya, a survey of adolescents showed that while 70 percent of boys had many friends in their neighborhood, this was true for only 50 percent of girls. Furthermore, although more than two-thirds of boys had a place outside their own home, their friends' homes, or school to meet same-sex friends, only onethird of girls did. ${ }^{2}$ In Ethiopia's Addis Ababa slums, 60 percent of boys have "many friends" compared with only 24 percent of girls. Half of boys have a place to meet same-sex friends, while only 13 percent of girls do. ${ }^{3}$ In rural Amhara, Ethiopia, 68 percent of boys compared with 59 percent of girls had many friends. Almost half of the boys there have a place to meet same-sex friends, as compared with 16 percent of the girls. ${ }^{4}$

Strengthening critical social assets, such as friends and mentors, lessens girls' health and economic risks.

High-quality programs for vulnerable girls and young women in disadvantaged communities build leadership skills and provide opportunities. Girls and young women living in the communities in which the programs are taking place must be nurtured until they have adequate skills to lead and mentor other girls in their community.

There are girls with leadership potential in every community in the world

Girls with leadership potential are an extremely valuable resource for the poorest communities because they have the potential to serve as leaders and mentors for other girls. The benefit of building girls' leadership abilities in these communities is three-fold. It provides heroes and role models for young girls, empowers and strengthens older girls, and challenges outmoded community norms.

Young girls need local leaders to look up to and emulate

When a girl has a crisis and needs someone to turn too, her mentor needs to be in the community, ready and able to respond. Too often program managers assume that leaders or mentors must be university students or young professional women imported from communities that are better off. These young women may be motivated and caring, but they do not provide an anchor of leadership within a disadvantaged community. For example, the schooling performance of 19-year-old girls in Africa is poorest in southern Africa. More than 40 percent of 19-yearold girls in Ghana have completed school, compared with about 2 percent in Mozambique. In most of Africa, at least 5 percent of girls have completed school by age $19 .{ }^{5}$ Girls who have completed school have leadership potential and can serve as mentors for younger girls in their community. These girls are not the only ones who can serve as mentors. Talent and drive exists in every community, even the poorest. More often it is the opportunities that must be created. Investments must be made to strengthen local, indigenous girls' leadership and to ensure that there is a cadre of young female leaders within the community.

The opportunity to be seen as a leader and mentor in a community changes a girl's view of herself

Having a visible role within the community and a sense of responsibility for younger girls is a positive force for change in the lives of young female leaders. ${ }^{6}$ Two such leaders in a girls' program in a slum area of Kenya said the following:
"The kids are relying on me; I have to show a good example. I am proud that I have the courage and morale to be with them. I am proud of their good behavior and that they know their rights."

"I enjoy it. They come to you for advice. You feel very important; you feel that you are somebody in the community."

The presence of a network of young female leaders (and a safe space that they regularly occupy) implicitly and explicitly challenges the power structure within a community and lends a strong female voice to decisionmaking structures in the community

Most poor communities are devoid of strong public female leadershipeither old or young women-or venues in which women can meet. Hallman found that girls' friendship networks were much less developed than boys' (typically, in South Africa the poorest boys had more friends and regular access to them than did the richest girls) and crucially, that greater social isolation was strongly correlated with girls experiencing forced sex. ${ }^{7,8}$

Creating leadership opportunities for girls and young women has the power to alter the positions of girls and women in the community and empower them to claim their rights. ${ }^{9}$ For example, a law was adopted in Guatemala in 1996 stating that all communities would have places where females can meet. When a cadre of female leaders is developed, they can begin to claim these spaces. Participating in such a leadership network increases the respect that girls and women receive from other community members. Girls in such positions have reported that they are no longer harassed by men because of the status they now have in the community. Putting young women into these positions is one of the paths through which gender norms are changed and the traditional structures and dynamics of power are challenged. 


\section{PROMOTED POLICIES AND PRACTICES}

\section{Cascading Leadership:}

Begin with the girls' leadership that exists where you are; build program models from there

One model of girls' leadership development that has worked in diverse settings-from urban slums in East Africa to the Mayan highlands in Guatemala to socially conservative Upper Egypt-is known as "cascading leadership." In this model, older adolescent girls and young women typically aged 18-30 are trained to mentor younger girls in their communities. Sometimes this takes place over a long period of time where girls graduate from the program and are trained to take on increasingly higher leadership positions, including running groups for new girls. In most first-generation programs, there is not enough time at the beginning to allow girls to go through the full program cycle as part of their leadership development, and it is necessary to train a group of older adolescent girls to serve as the initial mentors. The critical elements of a cascading leadership model are as follows:

\section{Train older adolescent girls or young} women to be leaders within their own communities and run programs for younger adolescent girls

In general, mentors are young women (typically ages 18-30) from the community with whom the girls can identify. In addition to implementing the curriculum, mentors serve as role models for the girls. In contrast to peer programs, which have been established for betteroff school-going populations, mentors are slightly older than the girls in the program. Even in distressed settings, there are frequently some girls who have gone further in school than others and have the skills needed to serve as mentors.

\section{Support mentors with appropriate compensation}

It is critical to note that mentors and group leaders should be compensated for their time and treated as if they are doing a job-which they are! Ideally they should be paid a small stipend appropriate for the number of hours they are involved. The amount can be linked to similar compensation for other jobs in the community, such as a daycare or health outreach worker, or a primary school teacher. ${ }^{10}$ If that is not possible, mentors and group leaders should be compensated with training, opportunities, or other agreed-upon incentives. Experience has shown, however, that a monetary stipend is the best way to ensure quality work, commitment, and sustainability. Mentors who are paid are more likely to show up for work, prepare well for group meetings, and provide ongoing support to girls at the community level.

\section{Provide mentors with ongoing supervision and support}

This can take the form of monthly mentors meetings, one-on-one meetings, or site visits, depending on the geographic reach of your program. We recommend some form of gathering that allows mentors to interact, share

\section{CASCADING LEADERSHIP MODEL}




successes and challenges-such as when girls disclose pressures from child marriage, incest, or violenceand exchange ideas and learning, and build their own social networks.

Involve girls in identifying the most appropriate content and delivery methods for their program

Girl leaders, especially those who have the ability to express themselves and have a critical analysis of their surroundings, will have the best insight into the issues, challenges, and barriers faced by other girls in their communities. They will also understand key topics that need to be covered. Do not overlook their input into the content of the program, the main issues that need to be addressed, safety concerns for girls, and more. Ask the leaders where and when girls can meet, which adults are critical in their lives, the seasonal events that put them at greater risk, such as school vacations and community festivals, and how the program can adapt to address their major concerns. ${ }^{11}$ The Population Council has developed a safety scan tool for use by girls and boys to define times of the day, week, season, or situation that are sources of threat. The safety scan tool lays the foundation for a practical discussion of what a safety plan might look like. ${ }^{12,13}$

Employ leaders and mentors who are themselves girls; they are often the most effective and sustainable in the long term in delivering content to other girls in their community

Regularly bringing girls safely together is the highest priority; the curriculum covered at these meetings nonetheless is important. Especially at the beginning, it should be provisional and evolving based on the needs of the participating girls. Content must be adapted to their skills and to programmatic requirements. Girl leaders and mentors will be able to deliver content in a language and style that is comprehendible and comfortable for the girl participants. The leaders' grasp of material and ability to transmit it to others is potentially a longterm community resource. Content and training materials used in one setting often need to be adapted to be appropriate for another setting. Do not underestimate the importance of these adjustments. Adapting the material to your local setting will make it easier for girl leaders to disseminate the contents, and will make the material more applicable to the lives of girls in the program. For example, financial-literacy program content may be set and even age-graded (basic modules for girls 10-14 and girls 15-19). The girl leaders delivering this content may have 30 minutes of instruction time per session. The sequencing of the material and its level needs to be carefully gauged and adapted to both the girl leaders' abilities and their working conditions. Furthermore, a plan needs to be in place to refresh their training and ensure some level of quality control on their work. ${ }^{14}$

Recognize that mentors and peer educators are two different models that serve different purposes

Mentors/Cascading Leadership involves older girls mentoring younger ones, so that even though all of them might be adolescents or young women, there is an age difference. For instance, a 24-year-old running a girls group of 12-14-year-olds, or a 15-year-old training a 10-year-old. What is critical is that the older girls are given a leadership role and set of responsibilities, and the younger girls see an example of what they can be in the future-something to work toward.

Peer education, on the other hand, implies the transfer of information from young people to their age mates. This model has been found to have benefits for the peer educators themselves, but less so for program participants. ${ }^{15,16}$ The peer-education model also tends to elevate less vulnerable youth into leadership positions, as those that are selected to be the peer educators are often already outstanding. Finally, peer education does not build a lasting structure of leadership and program-delivery infrastructure, because peer educators go through the program cycle and move on.

\section{Experiment with content once a structure is in place}

Girl leaders can be thought of as community extension workers. Because of their constant presence in the community, they have the ability to find and gain the trust of the girls who would benefit most from these programs. While not yet tried or evaluated, it would be useful to explore how this structure of leaders could be used in the health, civic, and financial sectors. In the health arena, it is possible to imagine that the girls might be able to deliver health information, commodities, referrals, and perhaps even vaccinations. For example, could girl leaders be trained to provide the HPV vaccine to adolescent girls in their communities? In the civic arena, could girl leaders be mobilized to ensure that all girls in their communities have the necessary identification documents (birth certificates, immunization cards). Can girl leaders serve as recognized "local leaders" who sign letters of verification for purposes of voting, account opening, and more? In the financial arena, can girl leaders be key figures in the delivery of financialeducation and financial-service provision?

This program model has been shown to be effective in both enriching the experience of girls-increasing their social networks and safety, and providing a source of support and future vision-as well as building positive leadership opportunities for older adolescent girls and young women themselves. Cascading leadership has not yet been tested in all circumstances in which it could succeed, however 
the potential is there and experimentation is encouraged.

\section{RESOURCES: LEARNING LAB PROGRAMS}

The Binti Pamoja (Daughters United) Center Safe Spaces Program: An asset-building program for adolescent girls aged 10-19, Kibera, Kenya

Binti Pamoja is a program for adolescent girls aged 10-19 in the Kibera slum of Nairobi, Kenya. The program started in 2002 with a core group of 15 girls that then expanded and split into two groups. After a couple of years as these girls grew along with the program, it became clear that they were ready to "graduate" and take on leadership roles, and the program was ready to expand into the community. In 2006, the initial group of graduates went through a training of trainers program that strengthened their skills in facilitation, group development, communication, and conflict resolution. Then the girls worked in pairs to form their own groups that met in the community. The responsibility of the mentors/alumni was to recruit girls into their groups, locate places in the community to meet, plan and facilitate weekly meetings, provide support and guidance to the girls in their group, and spend the monthly group budget appropriately. Alumni are provided with a small stipend and meet monthly for supervision meetings with the Binti Pamoja staff.

Within a year, the "Safe Spaces Program" at Binti Pamoja had grown to 20 alumni and 10 groups. When this became too large for the two program staff to handle, two alumni were hired as part-time field officers to monitor and support the alumni and safe spaces groups. Each year, the Safe Spaces Program continued to grow as more girls finished Binti's core program, became alumni, and started their own girls' groups in the community. By 2009, the program had more than 50 alumni and 25 groups-too much for two field officers to supervise. Therefore, another leadership level was implemented between alumni/group leaders and field officers-village coordinators. Each of the five village coordinators are responsible for a specific geographical area in Kibera and monitor 4 to 6 groups. They help the alumni with recruitment, identifying places to meet, monitoring group content, and planning events and trainings.

Through a cascading leadership model, Binti Pamoja has been able to grow from a program of 40 girls meeting in one location in Kibera to a program of more than 1,000 girls, 40 groups (20-30 per group), over 80 alumni in some leadership capacity, and a reach into every village within Kibera.

For further information, please visit the program's website, http://cfk. unc.edu/whatwedo/daughtersunited/.

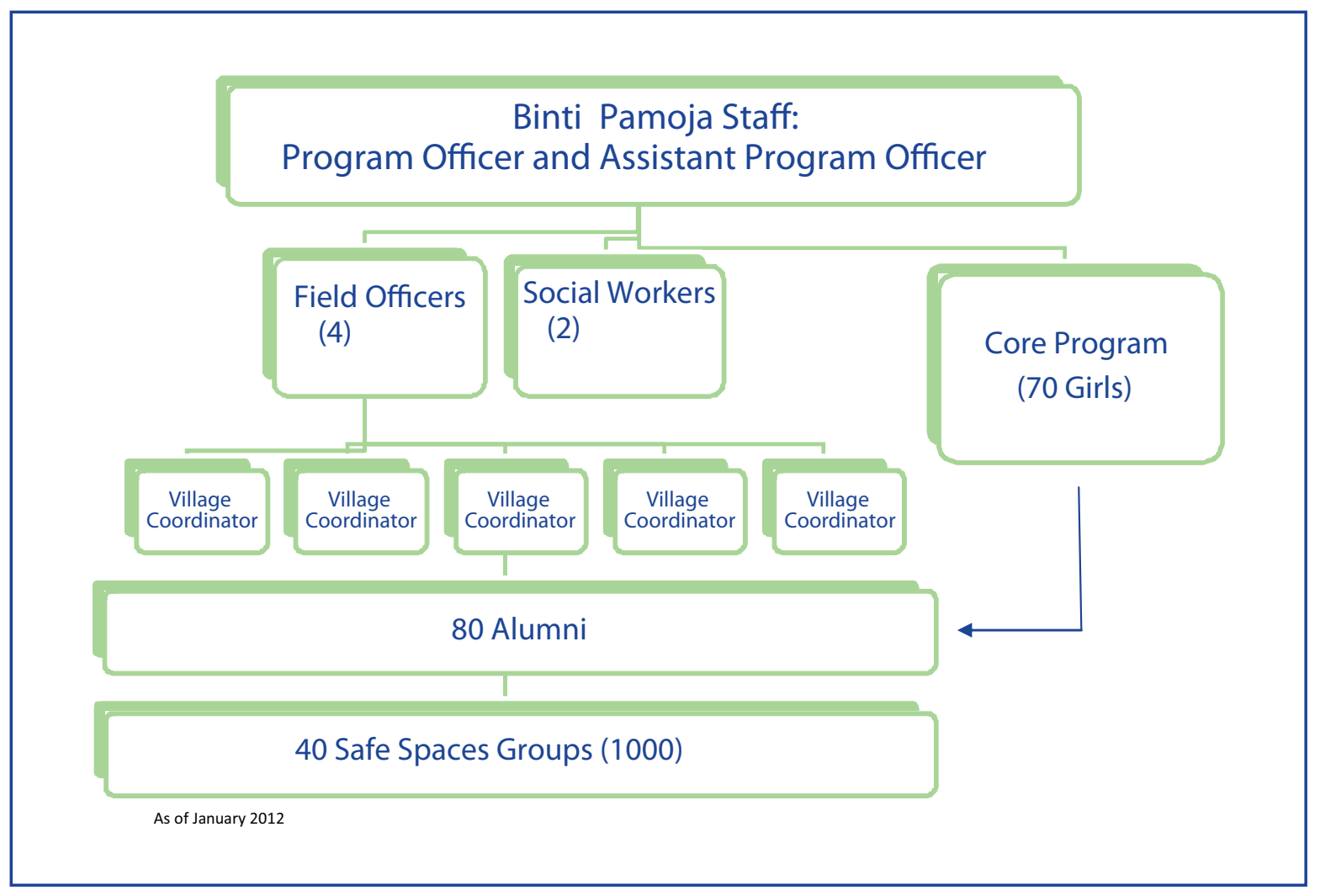


Safe and Smart Savings Products for Vulnerable Adolescent Girls in Kenya and Uganda: Building girls' leadership and access to financial products

This program, managed in partnership by the Population Council and MicroSave Consulting, Ltd., together with financial institution partners FauluKenya and K-Rep Bank in Kenya, and Finance Trust and FINCA-Uganda in Uganda, aims to provide adolescent girls with formal savings accounts. The accounts are delivered using the "Safe Spaces Model": Girls are organized into groups that meet each week, and during the weekly meetings the girls are trained on basic health and financial-education topics. Each group has a mentor-a young woman from the community who receives a small stipend, runs group meetings, and helps mobilize girls. The mentors go through an intensive training of trainers at the start of the program cycle. They are provided with financial education as well as training and group-management skills, and then have monthly supervision meetings with program staff.
This program is an example of cascading leadership that did not grow organically, because in the establishment of the program there was no time to wait for the girls in the savings groups to grow and then become mentors. Therefore, mentors were selected and trained both on the content they deliver to the girls, as well as leadership, communication, and group facilitation.

For the financial institutions, each branch that offers the product is supervised by a branch manager. One or two field officers are specifically responsible for the girls' savings accounts, and they liaise with the mentors. Depending on the financial institution, mentors oversee between one and four groups. Some of the financial institutions have contracted a community-based organization to facilitate the hiring and supervision of the mentors as well as ongoing girls' group meetings.

For further information, please contact Karen Austrian at kaustrian@ popcouncil.org, or visit the project's webpage at http://www.popcouncil. org/projects/48_SafeSmartSavings VulnerableGirls.asp.
Abriendo Oportunidades (Opening Opportunities): Program for rural, indigenous girls ages 8-18 from Guatemala's poorest communities

The Population Council's Abriendo Oportunidades is designed to reach and empower indigenous girls ages 8-18 from Guatemala's poorest rural communities. The program operates in two age cohorts: 8-12 and 13-18. A cascading leadership model is used at the community level where two young women ages 15-18 from each community lead each annual cycle of younger girls' club participants. An additional layer of leadership exists in some communities where there is leadership involvement from young, indigenous female interns from local NGOs. Girl leaders receive a stipend to guide club activities and serve as positive alternative role models at the community level. ${ }^{17}$

For further information, please contact Angel del Valle at adelvalle@ popcouncil.org, or visit the project's webpage at http://www.popcouncil. org/projects/244_CreateOpportunities Mayan.asp.

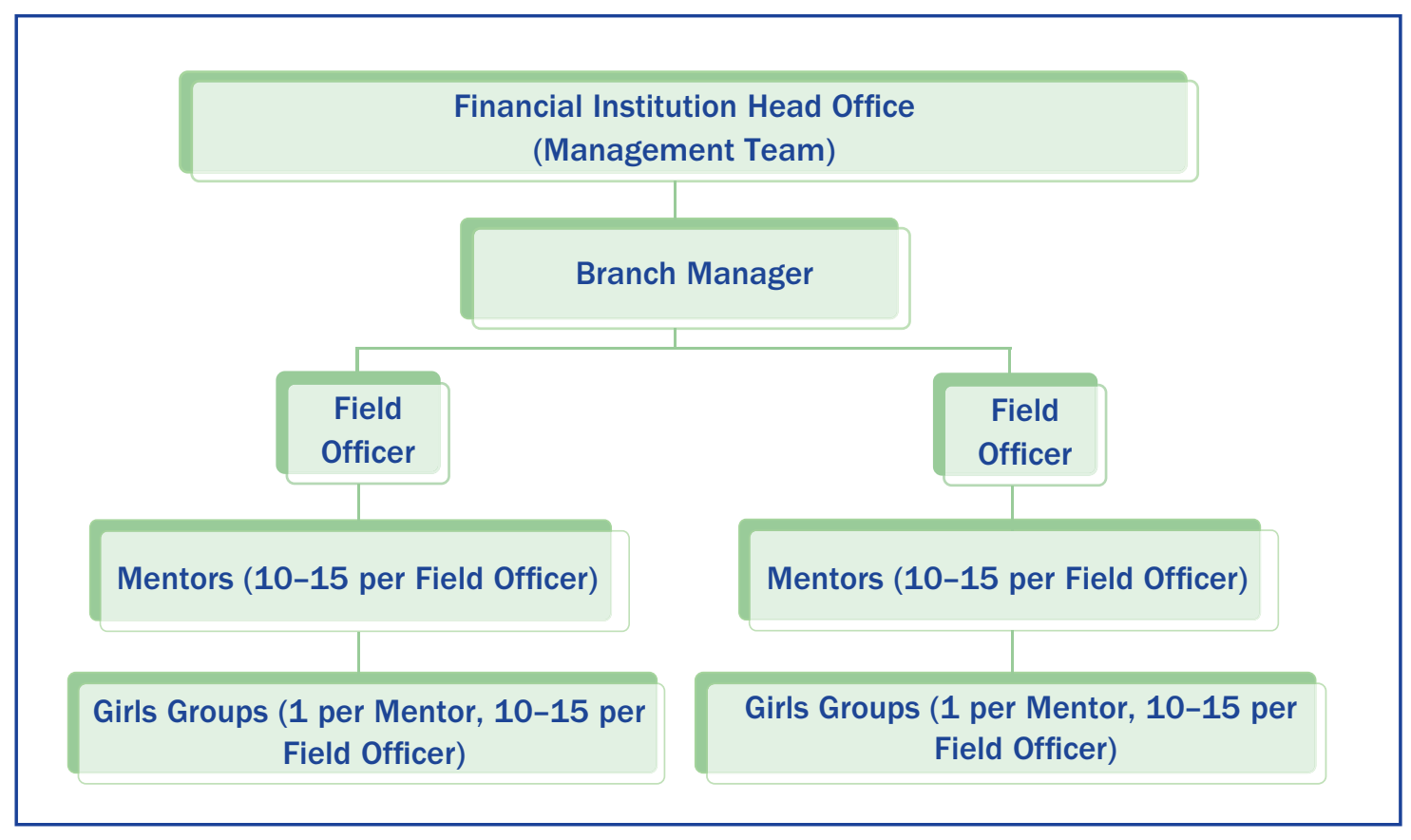


Biruh Tesfa (Bright Future):

Program for domestic workers and rural-urban migrants in Ethiopia's slum areas

In Ethiopia, poor adolescent girls often migrate to urban areas seeking work and educational opportunities or to escape an early marriage. Some have lost one or both parents to AIDS. They are often uneducated, socially isolated, and unprotected, and have come without their families. What they find is domestic work, where they are poorly paid and sometimes beaten or abused; some are forced into sex work. The girls have few friends, no one to go to for assistance, few opportunities for schooling, and no safe places to meet other girls and build networks of support. In partnership with the Addis Ababa Youth and Sport Commission and the Ethiopia Ministry of Youth and Sport, the Population Council designed and implements the "Biruh Tesfa" program for out-of-school slum-dwelling girls. The program mobilizes girls into groups that meet with adult female mentors in community spaces. Following training, mentors identify girls who are eligible for the program by going house to house in their assignment area. If mentors identify eligible girls in the household, they request their participation in the program. For those girls who are interested, mentors discuss participation with their parents, guardians, or-in the case of domestic workers-their employers, who frequently are not initially in favor of their participation. Mentors are responsible for following up on the girls they enroll in the program. Girls' groups meet at community halls and facilities donated by the local administration/kebele.

Girls receive training in literacy and numeracy, communication and self-esteem, hygiene and menstruation, disabilities, HIV and AIDS, reproductive health, financial literacy and savings, and gender-based violence, among other topics. All participating girls receive a project identification (ID) card with their photo. For many girls, this simple ID card is the only form of identification they have, and frequently the only picture of themselves. They also receive notebooks, pens, and pencils. Because of their extreme poverty, many beneficiaries lack basic commodities such as soap or sanitary napkins. Girls receive approximately four bars of soap a year, as well locally produced reusable sanitary napkins. Using a voucher system, Biruh Tesfa girls can receive subsidized or free medical services from a network of service providers. In addition, a new initiative aims to increase the participation of girls with disabilities. By April 2012, more than 55,000 girls had benefited from the Biruh Tesfa program in 18 cities in Ethiopia.

For further information, please contact Annabel Erulkar at aerulkar@ popcouncil.org, or visit the project's webpage at http://www.popcouncil.org/ projects/41_BiruhTesfaSafeSpaces.asp.

\section{RESOURCES: PUBLICATIONS AND TOOLS}

Austrian, K. and D. Ghati. 2010. GirlCentered Program Design: A Toolkit to Develop, Strengthen \& Expand Adolescent Girls Programs. (See Chapter 5 on leadership development and mentoring.) Nairobi: Population Council. http:// www.popcouncil.org/publications/ books/2010_AdolGirlsToolkit.asp.

Promoting Healthy, Safe, and Productive Transitions to Adulthood. Brief series. New York: Population Council. http:// www.popcouncil.org/publications/ serialsbriefs/TABriefs.asp.

- Brief No. 5: Equipping Mayan girls to improve their lives

- Brief No. 6: Addis Birhan project: Working with boys and men to address young girls' social vulnerability

- Brief No. 12: Scaling up assetbuilding programs for marginalized adolescent girls in socially conservative settings: The Ishraq program in rural Upper Egypt.
- Brief No. 15: Tap and Reposition Youth (TRY): Providing social support, savings, and microcredit opportunities for young women in areas with high HIV prevalence.

- Brief No. 21: Biruh Tesfa provides domestic workers, orphans, and migrants in urban Ethiopia with social support, HIV education, and skills

- Brief No. 30: Identifying sources of adolescent exclusion due to violence: Participatory mapping in South Africa.

\section{NOTES}

1 The National Surveys of Adolescence conducted by the Guttmacher Institute and country partners in Burkina Faso, Ghana, Malawi, and Uganda revealed data on density of friendship networks, showing that across all groups (rural/urban, schooling achievement), boys have more close friends on average than girls (Biddlecom, Ann. 2008. correspondence with researcher); Hallman, K. 2005.

"Gendered socioeconomic conditions and HIV risk behaviours among young people in South Africa," African Journal of AIDS Research 4(1): 37-50.

2 Erulkar, A. and J. Matheka. 2007. Adolescence in the Kibera Slums of Nairobi Kenya. Population Council.

3 Erulkar, A. et al. 2004. Adolescent Life in Low Income \& Slum Areas of Addis Ababa, Ethiopia. Population Council.

4 Erulkar, A. et al. 2004. The Experience of Adolescence in Rural Amhara Region, Ethiopia. Population Council.

5 Lloyd, Cynthia B. 2009. New Lessons. New York: Population Council.

6 Salem, Rania, Barbara Ibrahim, and Martha Brady. 2003. "Negotiating leadership roles: Young Women's Experiences in rural Upper Egypt," Women's Studies Quarterly 31(3/4): 174-191.

7 Hallman, Kelly. 2008. "Social exclusion: The gendering of HIV risk in KwaZuluNatal, South Africa." Working paper. New York: UNESCO and Social Science Research Council.

8 Bruce, Judith and Kelly Hallman. 2008. "Reaching the girls left behind," Gender \& Development 16(2): 227-245. 
9 Austrian, Karen, C. Ngurukie, and C. Sakwa. 2009. "Integrating Financial Education and Savings Opportunities into Health Interventions for Adolescent Girls in the Kibera Slum of Nairobi, Kenya." Paper presented at International Conference on Urban Health: Meeting Urban Health Needs Through Innovative Research, Policies, and Interventions. Nairobi, Kenya.

10 Sewall-Menon, Jessica, Judith Bruce, et al. 2012. "The cost of reaching the most disadvantaged girls: Programmatic evidence from Egypt, Ethiopia, Guatemala, Kenya, South Africa, and Uganda." New York: Population Council.

11 For example, when designing the Safe and Smart Savings Products program (see below), a market-research study was conducted with more than 200 girls from different segments (older, younger, in school, out of school). The study gathered opinions not only on savings account features but also on nonfinancial services, training topics, and program logistics.

12 Austrian, Karen and Dennitah Ghati. 2010. Girl-Centered Program Design: A Toolkit to Develop, Strengthen \& Expand Adolescent Girls Programs. Nairobi: Population Council. (Safety scan conceptualized by Judith Bruce and Karen Austrian.)

13 Bruce, Judith. 2012. “Violence against adolescent girls: A fundamental challenge to meaningful equality," a Girls First! Review. New York: Population Council.

14 For example, in Binti Pamoja mentors meet monthly with field officers to share successes and challenges; on a quarterly basis, they revise their work plans based on the needs of their groups. In the Safe and Smart Savings
Products program, monthly one-day refresher training sessions are provided to mentors on topics they self-identify as gaps in skills or knowledge.

15 Horizons/Population Council. 1999. "Peer Education and HIV/AIDS: Past Experience, Future Directions." Washington, DC, and New York: Population Council.

16 Adamchak, Susan. "Youth Peer Education in Reproductive Health and HIV/ AIDS: Progress, Process, and Programming for the Future. Youth Issues Paper No. 7." Arlington, VA: Family Health International/YouthNet Program.

17 Catino, Jennifer. 2012. "The health of vulnerable adolescent girls: A strategic investment for double return," a Girls First! Review. New York: Population Council. 



\section{(1) Population Council}

The Population Council confronts critical health and development issues-from stopping the spread of HIV to improving reproductive health and ensuring that young people lead full and productive lives. Through biomedical, social science, and public health research in 50 countries, the Council works with our partners to deliver solutions that lead to more effective policies, programs, and technologies that improve lives around the world. Established in 1952 and headquartered in New York, the Council is a nongovernmental, nonprofit organization governed by an international board of trustees.

www.popcouncil.org 